\title{
Estimativa da capacidade de armazenamento de água no solo para a microrregião da BAP (MT)
}

Com o aumento da população mundial surge a preocupação com o mau uso dos recursos naturais, como o principal a água, este é essencia para o consumo e para uso na agricultura. Portanto, urge a necessidade de se estudar as regiões onde são aptas a utilizar a água como fonte de irrigação para as culturas. O trabalho foi realizado no laboratório de Agrometeorologia na Universidade do Estado do Mato Grosso (UNEMAT), com auxílio do software Geoestatístico ArcGis $10^{\circledR}$, que interpola e especializa os dados georreferenciados formando mapas. A Bacia do Alto Paraguai pertencente ao Estado do Mato Grosso possui 44 municípios sendo eles classificados de acordo com o tipo de solo e estabelecidos três padrões de CAD 30, 50 e 75. Contudo tem-se a determinação da área e representatividade para cada município onde 31 destes representam mais de $41 \%$ de todo território com solo CAD 75. Porém somente 8 apresentam CAD 50 com 11\% sendo estes localizado na área de alagamento e CAD 30 se dispõe em 37 municípios representando 48\%. Portanto, essa região apresenta em sua maior parte uma CAD de 75, o que demostra a presença de um solo com maior capacidade de armazenamento e disponibilidade de água

Palavras-chave: Água Disponível; Classificação do Solo; Georreferenciamento; Representatividade.

\section{Water storage capacity estimate in soil for the BAP (MT) microregion by alternative methodology}

\begin{abstract}
With the increase in world population comes the concern about the misuse of natural resources, such as the primary resource of water, essential for consumption and use in agriculture. Thus, there is an urgent need to study the regions where it is possible to use water as a source of irrigation for crops. This work was performed in the laboratory of Agrometeorology at the State University of Mato Grosso (UNEMAT), with the aid of ArcGIS $10^{\circledR}$ geostatistical software, which interpolates and specializes georeferenced data in order to form maps The Upper Paraguay River Basin, belonging to the State of Mato Grosso, has 44 municipalities which are classified according to the type of soil, establishing three AWC standards: 30,50 and 75. Overall, the area and representativeness for each municipality were determined, and 31 of these, representing over $41 \%$ of the whole territory, were shown to have AWC 75 soil. Only 8 municipalities were shown to have AWC 50 soil, with $11 \%$ of these being located in a flood zone, and 37 municipalities were shown to have AWC 30 soil, representing $48 \%$ of the total. Therefore, this region mostly has AWC 75 soil, demonstrating the presence of a soil with higher storage capacity and water availability.

Keywords: Available Water; Soil Classification; Georeferencing; Representativeness.
\end{abstract}

Topic: Química Agrícola e Ambiental

Reviewed anonymously in the process of blind peer.
Received: $18 / 04 / 2016$

Approved: 20/05/2016
João Danilo Barbieri

Universidade Estadual de Maringá, Brasil http://lattes.cnpq.br/1216189174259554 jdanilob@gmail.com

\section{Rivanildo Dallacort}

Universidade do Estado de Mato Grosso, Brasil http://lattes.cnpq.br/1292986021348016 rivanildo@unemat.br

Tiago Oliveira

Universidade do Estado de Mato Grosso, Brasil http://lattes.cnpq.br/8228234058635598 tiagobersanini@gmail.com

\author{
Rafael Cesar Tieppo \\ Universidade de São Paulo, Brasil \\ http://lattes.cnpq.br/3275865819287843 \\ rafaelt@unemat.br \\ Dejânia Vieira Araújo \\ Universidade Federal de Lavras, Brasil \\ http://lattes.cnpq.br/3826330763207301 \\ dejania@unemat.br
}

Referencing this:

BARBIERI, J. D.; DALLACORT, R.; OLIVEIRA, T.; TIEPPO, R. C.; ARAÚJO, D. V.. Estimativa da capacidade de armazenamento de água no solo para a microrregião da BAP (MT). Revista Ibero-Americana de Ciências Ambientais, v.8, n.1, p.21-28, 2017. DOI: http://doi.org/10.6008/SPC2179-6858.2017.001.0002 


\section{INTRODUÇÃO}

Os impactos ambientais causados pelo mau aproveitamento dos recursos naturais, agravam o sistema produtivo a longo prazo, provocando a necessidade do aumento da produtividade, essas necessidades vêm despertando maiores interesses no desenvolvimento de estratégia que visam sustentabilidade (JACOBI, 2003).

Para o planejamento das atividades agrícolas como, a escolha da cultura e a melhor época de semeadura, é fundamental o conhecimento das propriedades físicas, químicas e biológicas dos solos. Este conhecimento é importante, visto que as plantas necessitam de solos bem estruturados, sendo por isso a seleção e a utilização adequada de cada tipo de solo de fundamental importância para a manutenção da qualidade e da produtividade do sistema (MARCHÃO et al. 2007; BOGNOLA et al. 2010).

A BAP (Bacia do Alto Paraguai) ocupa no território brasileiro uma área aproximada de $363.000 \mathrm{~km}^{2} \mathrm{e}$ deste total mais de 47\% estão localizados dentro do Estado de Mato Grosso. Segundo Longhi et al. (2006), o Pantanal brasileiro está totalmente inserido na bacia do Alto Paraguai constitui uma importante relação entre os biomas Cerrado e Pantanal apresentando características sociais e econômicas que não são encontradas em outras regiões do mundo.

A retenção de água no solo ocorre devido a fenômenos de capilaridade e adsorção, sendo que a capilaridade atua na retenção da água quando os poros estão cheios (solo úmido) e a adsorção passa a predominar na retenção à medida que os poros vão se esvaziando (REICHARDT \& TIMM, 2004). A capacidade de retenção de água na zona radicular de uma determinada cultura depende, basicamente, da textura e da estrutura do solo, da profundidade efetiva deste sistema e da profundidade da camada de solo (BERNARDO et al. 2006).

Tradicionalmente, a capacidade de campo (CC) e o ponto de murcha permanente (PMP) são considerados como os limites máximo e mínimo, respectivamente, de água disponível. A partir desses limites, pode-se determinar a capacidade de armazenamento de água disponível no solo, considerando a profundidade do sistema radicular (BERGAMASCHI et al. 1992).

Para sua elaboração, há necessidade de se definir, para uma determinada região ou local a capacidade de água disponível (CAD) no solo, os valores de precipitação $(P)$ e evapotranspiração de referência (ETo) para um período considerado. Com essas informações básicas, a metodologia permite estimar, para o mesmo período, o armazenamento da água no solo (ARM), a evapotranspiração real (ER), deficiência (DEF) e excedente hídrico (EXC) (PEREIRA et al., 2002; ARAUJO et al., 2004).

Frizzone et al. (2005) estudando o planejamento da irrigação afirma que a quantidade de água necessária para o perfeito desenvolvimento das culturas é um parâmetro importante para o correto planejamento, dimensionamento e manejo de um sistema de irrigação. Neste sentido, a literatura tem mostrado que o balanço hídrico se constitui em uma ferramenta interessante para estimar a lâmina de irrigação ideal, pois se baseia na dinâmica do armazenamento de água no solo e ainda pode ser realizado considerando apenas dados climáticos básicos, tais como a chuva e a temperatura do ar (PEREIRA, 2005). 
Diversos autores definem balanço hídrico como sendo a contabilidade hídrica do solo, ou seja, o cômputo de todos os ganhos e perdas de água, juntamente com o seu armazenamento, que se verificam no solo ou bacia considerada, para tanto é fundamental o conhecimento de como cada característica de solo se comporta com relação à entrada e saída de água, resultando esse processo as características edafoclimáticas.

Este trabalho tem como objetivo estimar a capacidade de água disponível (CAD), de forma espacializada, para as classes de solos representados na microrregião da Bacia do Alto Paraguai para o Estado de Mato Grosso.

\section{METODOLOGIA}

O trabalho foi desenvolvido na Universidade do Estado do Mato Grosso (UNEMAT) campus de Tangará da Serra especificamente no Centro de Pesquisas, Estudos e Desenvolvimento Agroambientais

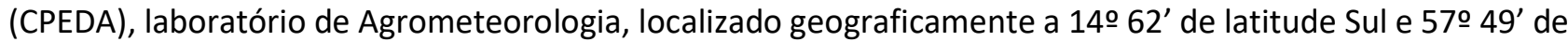
longitude Oeste, com altitude média de 321 metros, segundo dados do Instituto Nacional de Meteorologia (INMET).

Em estudos realizados por Sans et al. (2001) os mapas de solo são, normalmente, de reconhecimento e em escalas muito pequenas, dificultando a espacialização do balanço hídrico. Portanto, ao espacializar informações físico-hídricas utilizando esses mapas, pode-se estar incorrendo em grandes erros, não só pela representatividade da classe de solo, mas também pela omissão de unidades de solo considerando a escala. Assim sendo, a solução é agrupar os solos em classes de disponibilidade de água e fazer o balanço hídrico para cada agrupamento de solos, ou para cada classe isoladamente.

Com auxílio do programa ArcGis $10^{\circ}$ foram recortados os mapas da microrregião da Bacia do Alto Paraguai (BAP) representada no estado do Mato Grosso, os tipos de solos foram plotados e agrupados de acordo com as classificações do solo, propostas por Sans et al. (2001), adaptando em três diferentes capacidades de água disponível (CAD) 30, 50, 75 mm, de acordo com a característica local (Tabela 1).

Tabela 1: Classificação dos solos de Mato Grosso quanto à capacidade de água disponível (Adaptado de Sans et al., 2001).

\begin{tabular}{|c|c|}
\hline Grupo & Classe de solo \\
\hline Baixa & $\begin{array}{l}\text { Solos Aluviais } \\
\text { Areias Quartzosas } \\
\text { Areias Quartzosas Hidromórficas } \\
\text { Plintossolo } \\
\text { Solos Litólicos } \\
\text { Solos Concrecionários Câmbicos } \\
\text { Solos Concrecionários Latossolicos } \\
\text { Solos Concrecionários Podzólicos }\end{array}$ \\
\hline Média & $\begin{array}{l}\text { Brunizem Avermelhado } \\
\text { Planossolo }\end{array}$ \\
\hline Alta & $\begin{array}{l}\text { Cambissolo } \\
\text { Glei Pouco Húmico } \\
\text { Latossolo Vermelho-Escuro } \\
\text { Latossolo Roxo } \\
\text { Latossolo Vermelho-Amarelo Podzólico } \\
\text { Latossolo Vermelho-Amarelo Podzólico } \\
\text { Podzólico Amarelo } \\
\text { Podzólico Vermelho-Escuro }\end{array}$ \\
\hline
\end{tabular}


Podzólico Vermelho-Amarelo

Terra Roxa Estruturada

Legenda: Baixa- solo de baixa retenção de água: solos com menos de $5 \%$ de água disponível, representado pelas areias quartzosas, (solos com mais de $60 \%$ de areia e teores de argila menores do que 15\%); Média- solos de média retenção de água: solos entre 5 e $15 \%$ de água disponível (teores de argila entre 15 a 35\%); Alta- solos com alta retenção de água: solos com mais de $15 \%$ de água disponível (teores de argila maiores que $35 \%$ ).

\section{RESULTADOS}

Para a determinação da capacidade de armazenamento de água no solo considerou-se apenas as áreas não alagáveis da região estudada, sendo que as mesmas foram identificadas como a totalidade do município de Barão de Melgaço, 59\% de Cáceres, 29\% de Curvelândia, 42\% de Itiquira, 3\% de Lambari D’oeste, 21\% de Nossa Senhora do Livramento, 83\% de Poconé, 3\% de Porto Estrela 19\% de Rondonópolis e 77\% de Santo Antônio do Leverger, totalizando assim, uma área de aproximadamente $55.451 \mathrm{~km}^{2}$ representando 32\% da Bacia do Alto Paraguai localizada no Estado de Mato Grosso.

Com o auxílio de um programa geoestatistico $\mathrm{ArcGis} 10^{\circledR}$ foi determinado a área e a porcentagem de cada nível de CAD dentro dos municípios pertencentes à BAP no Estado de Mato Grosso conforme representado na Tabela 2.

Tabela 2: Localização e dimensão da área em $\mathrm{km}^{2}$ para cada classe de Capacidade de Armazenamento de água, nos municípios da Bacia do alto Paraguai.

\begin{tabular}{|c|c|c|c|c|c|c|c|c|c|c|c|}
\hline \multirow{2}{*}{ NOME } & \multirow{2}{*}{ LAT. } & \multirow{2}{*}{ LON. } & \multirow{2}{*}{ Área Tot. } & \multicolumn{2}{|c|}{ CAD30 } & \multicolumn{2}{|c|}{ CAD50 } & \multicolumn{2}{|c|}{ CAD75 } & \multicolumn{2}{|c|}{$\%$} \\
\hline & & & & $\mathrm{Km}^{2}$ & $\%$ & $\mathrm{Km}^{2}$ & $\%$ & $\mathrm{Km}^{2}$ & $\%$ & Seca & Úmida \\
\hline Acorizal & -15.21 & -56.37 & 841.6 & 385.5 & 45.8 & & 0.0 & 456.1 & 54.2 & 100 & 0 \\
\hline Alto Paraguai & -14.51 & -56.48 & 2052.9 & 625.8 & 30.5 & & 0.0 & 1427.0 & 69.5 & 100 & 0 \\
\hline Araputanga & -15.47 & -58.35 & 1604.0 & 309.7 & 19.3 & & 0.0 & 1294.4 & 80.7 & 100 & 0 \\
\hline Arenápolis & -14.45 & -56.85 & 414.0 & & 0.0 & & 0.0 & 414.0 & 100.0 & 100 & 0 \\
\hline Barão de Melg. & -16.28 & -55.96 & 11054.2 & 5300.9 & 48.0 & 5265.1 & 47.6 & 488.2 & 4.4 & 0 & 100 \\
\hline Barra do Bugres & -15.07 & -57.18 & 5457.6 & 2622.4 & 48.1 & & 0.0 & 2835.2 & 52.0 & 100 & 0 \\
\hline Cáceres & -16.07 & -57.68 & 23582.6 & 10396.4 & 44.1 & 5741.5 & 24.4 & 7444.8 & 31.6 & 41 & 59 \\
\hline Ch. dos Guimarães & -15.46 & -55.75 & 5637.4 & 4242.1 & 75.3 & & 0.0 & 1395.3 & 24.8 & 100 & 0 \\
\hline Cuiabá & -15.60 & -56.10 & 3538.0 & 2621.5 & 74.1 & & 0.0 & 916.5 & 25.9 & 99 & 1 \\
\hline Curvelândia & -15.61 & -57.92 & 749.3 & 356.4 & 47.6 & & 0.0 & 393.0 & 52.4 & 71 & 29 \\
\hline Denise & -14.74 & -57.05 & 1301.7 & & 0.0 & & 0.0 & 1301.7 & 100.0 & 100 & 0 \\
\hline Dom Aquino & -15.81 & -54.92 & 2208.0 & 516.2 & 23.4 & & 0.0 & 1691.8 & 76.6 & 100 & 0 \\
\hline Figueirópolis D' Oeste & -15.45 & -58.74 & 890.6 & & 0.0 & & 0.0 & 890.6 & 100.0 & 100 & 0 \\
\hline Glória D' Oeste & -15.77 & -58.36 & 846.3 & & 0.0 & 47.5 & 5.6 & 798.8 & 94.4 & 100 & 0 \\
\hline Indiavaí & -15.49 & -58.57 & 599.2 & 5.9 & 1.0 & & 0.0 & 593.2 & 99.0 & 100 & 0 \\
\hline Itiquira & -17.21 & -54.15 & 8625.3 & 5119.8 & 59.4 & 145.7 & 1.7 & 3359.8 & 39.0 & 58 & 42 \\
\hline Jaciara & -15.97 & -54.97 & 1657.5 & & 0.0 & & 0.0 & 1657.5 & 100.0 & 99 & 1 \\
\hline Jangada & -15.24 & -56.49 & 1021.4 & 105.1 & 10.3 & & 0.0 & 916.3 & 89.7 & 100 & 0 \\
\hline Jaurú & -15.34 & -58.87 & 1311.2 & 177.0 & 13.5 & & 0.0 & 1134.2 & 86.5 & 100 & 0 \\
\hline Juscimeira & -16.05 & -54.88 & 2205.2 & 242.3 & 11.0 & & 0.0 & 1962.9 & 89.0 & 100 & 0 \\
\hline Lambari D' Oeste & -15.32 & -58.00 & 1335.5 & 202.6 & 15.2 & & 0.0 & 1132.9 & 84.8 & 100 & 0 \\
\hline Mirassol D' Oeste & -15.68 & -58.10 & 1072.8 & 6.9 & 0.6 & & 0.0 & 1066.0 & 99.4 & 97 & 3 \\
\hline Nortelândia & -14.46 & -56.80 & 1352.1 & 264.4 & 19.6 & & 0.0 & 1087.8 & 80.5 & 100 & 0 \\
\hline N. Sra. do Livramento & -15.78 & -56.35 & 5189.4 & 2656.4 & 51.2 & 27.0 & 0.5 & 2506.0 & 48.3 & 79 & 21 \\
\hline Nova Brasilândia & -14.96 & -54.97 & 3291.8 & 547.1 & 16.6 & & 0.0 & 2744.8 & 83.4 & 100 & 0 \\
\hline Nova Marilândia & -14.36 & -56.97 & 1939.6 & 1290.4 & 66.5 & & 0.0 & 649.1 & 33.5 & 100 & 0 \\
\hline Nova Olímpia & -14.80 & -57.29 & 1567.2 & 41.8 & 2.7 & & 0.0 & 1525.4 & 97.3 & 100 & 0 \\
\hline Pedra Preta & -16.62 & -54.47 & 4191.5 & 1546.9 & 36.9 & & 0.0 & 2644.6 & 63.1 & 100 & 0 \\
\hline Poconé & -16.26 & -56.62 & 16920.8 & 6589.7 & 38.9 & 6696.3 & 39.6 & 3634.9 & 21.5 & 17 & 83 \\
\hline Porto Esperidião & -15.85 & -58.46 & 5811.4 & 1296.8 & 22.3 & 17.2 & 0.3 & 4497.3 & 77.4 & 100 & 0 \\
\hline Porto Estrela & -15.32 & -57.23 & 2063.8 & 662.6 & 32.1 & & 0.0 & 1401.2 & 67.9 & 97 & 3 \\
\hline Poxoréo & -15.84 & -54.39 & 6918.4 & 3516.0 & 50.8 & & 0.0 & 3402.5 & 49.2 & 100 & 0 \\
\hline Reserva do Cabaçal & -15.08 & -58.47 & 1059.2 & 915.9 & 86.5 & & 0.0 & 143.3 & 13.5 & 100 & 0 \\
\hline Rio Branco & -15.24 & -58.12 & 528.2 & & 0.0 & & 0.0 & 528.2 & 100.0 & 100 & 0 \\
\hline Rondonópolis & -16.47 & -54.64 & 4167.5 & 982.5 & 23.6 & & 0.0 & 3185.0 & 76.4 & 81 & 19 \\
\hline Rosário Oeste & -14.84 & -56.43 & 8033.0 & 3448.5 & 42.9 & & 0.0 & 4584.5 & 57.1 & 100 & 0 \\
\hline
\end{tabular}




\begin{tabular}{|c|c|c|c|c|c|c|c|c|c|c|c|}
\hline Salto do Céu & -15.13 & -58.13 & 1772.5 & 284.3 & 16.0 & & 0.0 & 1488.2 & 84.0 & 100 & 0 \\
\hline Santo Afonso & -14.50 & -57.00 & 1170.6 & 568.0 & 48.5 & & 0.0 & 602.7 & 51.5 & 100 & 0 \\
\hline Sto. Ant. do Leverger & -15.87 & -56.08 & 12247.0 & 8300.3 & 67.8 & 335.4 & 2.7 & 3611.3 & 29.5 & 23 & 77 \\
\hline São José do Povo & -16.47 & -54.26 & 444.0 & 89.6 & 20.2 & & 0.0 & 354.3 & 79.8 & 100 & 0 \\
\hline São Pedro da Cipa & -16.00 & -54.92 & 343.7 & 209.0 & 60.8 & & 0.0 & 134.7 & 39.2 & 100 & 0 \\
\hline S. J. dos Quatro Marcos & -15.62 & -58.18 & 1280.9 & & 0.0 & & 0.0 & 1280.9 & 100.0 & 100 & 0 \\
\hline Tangará da Serra & -14.62 & -57.49 & 11567.6 & 3755.0 & 32.5 & & 0.0 & 7812.6 & 67.5 & 100 & 0 \\
\hline Várzea Grande & -15.65 & -56.13 & 938.3 & 630.0 & 67.1 & & 0.0 & 308.3 & 32.9 & 100 & 0 \\
\hline
\end{tabular}

A BAP apresenta uma área total de aproximadamente 363442 km² em território nacional e 172096 km2 para o Estado de Mato Grosso sua representatividade está expressa em 44 municípios sendo 31 destes apresentam mais de $50 \%$ de seu território com solo CAD 75, porém somente 8 apresentam CAD 50 sendo estes localizado na área de alagamento onde ocorre a preservação e impossibilidade de ação agrícola.

Portanto tem-se a necessidade de realizar analises locais para determinar exatamente a capacidade que o solo possui em disponibilizar água para a planta, contudo observamos uma maior amplitude e representatividade de solos com CAD 75 e CAD 30 para a região estudada, o que pode ser observado na Figura 1.

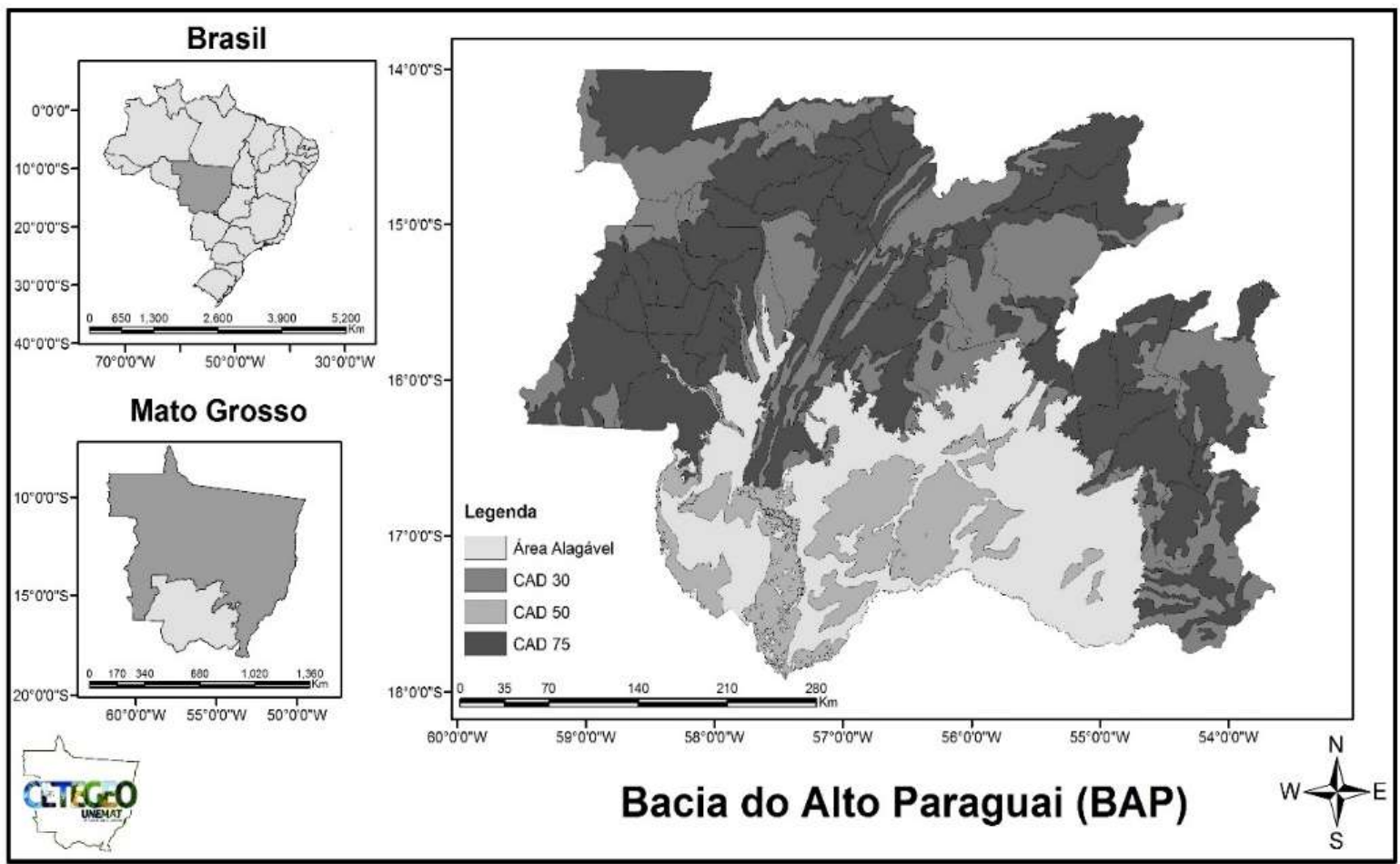

Figura 1: Representação das classes de Capacidade de Água Disponível para os municípios da região da Bacia do Alto Paraguai para o Estado de Mato Grosso.

\section{DISCUSSÃO}

Segundo Gonçalves et al., (2011) o fato de um solo com alto conteúdo de silte reter mais água disponível que um solo com alto conteúdo de areia é natural, assim como um solo argiloso retém mais água disponível que um solo arenoso, uma vez que no solo arenoso, os mecanismos de retenção de água de forma global, ou seja, capilaridade e adsorção às partículas de solo, são menos eficientes que no primeiro.

Em relação aos solos argilosos, no entanto, apesar de reterem muita umidade, grande parte desta água é retida a tensões elevadas, acima do PMP o que dificulta a disponibilidade as plantas. As propriedades 
físicas do solo com relação à capacidade de absorção, retenção e disponibilidade de água para as plantas, foram dispostas conforme descrito por Tormena et al. (1998).

Solos de textura fina, com alto conteúdo de matéria orgânica, e bem estruturados, tendem a reter muita água na capacidade de campo. No entanto, o teor de água que permanecerá neste solo, no ponto de murcha permanente, pode ser também alto, o bastante para que a água disponível seja menor que em outro solo com menor capacidade total de retenção de água. Às vezes tal fato é esquecido e aceita-se que a capacidade de armazenamento de água disponível normalmente cresce à medida que a textura do solo se torna mais fina. No entanto, é possível que solos siltosos retenham mais água disponível que solos arenosos, e também mais que solos argilosos.

Ruiz et al. (2003), procurando estudar o efeito destes parâmetros no armazenamento de água, verificaram que em solos com conteúdo de argila entre 13 e 20\%, a matéria orgânica influencia a capacidade de armazenamento de água disponível mais do que o conteúdo de silte.

Assim, solos argilosos ricos em matéria orgânica podem ter alta capacidade de armazenamento de água disponível, se houver esta estrutura. Em caso contrário, o armazenamento total é alto, mas a disponibilidade tende a ser pequena.

A capacidade efetiva de armazenamento de água no solo é definida como sendo a diferença entre o conteúdo de água retido no solo entre a capacidade de campo e o ponto de murcha permanente. Ruiz et al., (2003) utilizaram esse conceito baseando-se no fato de que a capacidade de campo não é uma constante, mas geralmente assume-se que ela corresponde a um potencial entre $-10 \mathrm{kPa}$ e $-33 \mathrm{kPa}$. Assumiram, também, que o ponto de murcha permanente, o ponto no qual uma planta murcha e não se recupera mais, geralmente corresponde a um potencial de $-1500 \mathrm{kPa}$.

Klein et al. (2006) determinando a água disponível em Latossolos observou que a água entre a capacidade de campo e o ponto de murcha permanente é denominada água disponível no solo (DTA ou CAD). Para os objetivos da irrigação, pode ser denominada Disponibilidade Total de Água no Solo (DTA).

Conforme descrito por Tormena et al. (1998) o manejo de recursos em áreas específicas, a distribuição espacial de valores de densidade do solo pode fornecer subsídios para a tomada de decisão sobre a adoção de práticas de descompactação do solo. Tais práticas poderiam ser conduzidas somente naquelas áreas onde a relação entre valores de densidade e Intervalo Ótimo de Potencial da Água no Solo (IOP) mostram a condição física desfavorável ao desenvolvimento das plantas, segundo determinado critério de manejo. De forma semelhante, o manejo da água pode ser realizado levando-se em conta a distribuição espacial da densidade do solo, o que permite descrever a distribuição espacial do IOP.

Para a utilização eficaz desses conceitos no contexto da agricultura de precisão, a distribuição espacial das variáveis deve ser identificada, o que pode ser implementado com o uso de técnicas geoestatísticas que nesse trabalho está disposto na região em estudo. 


\section{CONCLUSÕES}

A bacia do alto Paraguai no estado do Mato Grosso apresenta 32\% de área alagável o que não possibilita a atividade agrícola no período chuvoso, o solo possui CAD 50 para 98\% dessa área.

Os municípios Barão de Melgaço, Cáceres, Poconé, e Santo Antônio do Leverger possuem em seu território área alagada representada em mais de 50\% da área do município, esses municípios apresentam as três classificações de CAD.

A maior representatividade territorial apresenta CAD 75 o que confirma um maior armazenamento de água e disponibilidade para as plantas caracterizando o solo como apto para uso agrícola em relação disponibilidade hídrica.

\section{AGRADECIMENTOS}

Ao auxílio financeiro e bolsa do projeto de pesquisa Aplicação e transferência de tecnologias na otimização de sistemas agrícolas sustentáveis, Processo CNPp 564112/2010-0, edital MCT / CNPq / FNDCT / FAPs / MEC / CAPES /PRO-CENTRO-OESTE № 031/2010.

\section{REFERÊNCIAS}

ARAÚJO, M. A.; TORMENA, C. A.; SILVA, A. P.. Propriedades físicas de um Latossolo Vermelho distrófico cultivado e sob mata nativa. Revista Brasileira de Ciência do Solo, Viçosa, v.28, n.1, p.337-345, 2004.

BERGAMASCHI, H.; BERLATO, M. A.; MATZENAUER, R.; FONTANA, D. C.; CUNHA, G. R.; SANTOS, M. L. V.; FARIAS, J. R. B.; BARNI, N. A.. Agrometeorologia aplicada à irrigação. Porto Alegre: Editora da Universidade, 1992.

BERNARDO, S.; SOARES, A. A.; MANTOVANI, E. C.. Manual de irrigação. 8a ed. atualizada e ampliada. Viçosa: EdUFV, 2006.

BOGNOLA, I. A.; DEDECEK, R. A.; LAVORANTI, O. J.; HIGA A. R.. Influência de propriedades físico-hídricas do solo no crescimento de Pinus taeda. Pesquisa Florestal Brasileira, v.3, n.30, p.37-49, 2010.

FRIZZONE, J. A.; ANDRADE JÚNIOR, A. S.; SOUZA, J. L. M.; ZOCOLER, J. L.; Planejamento da Irrigação: análise de decisão de investimento. Brasília: Embrapa, 2005.

GONÇALVES, A. C. A.; TRINTINALHA, M. A.; TORMENA, C. A.; FOLEGATTI, M. V.. Influência da densidade do solo na estimativa do conteúdo de água de um Nitossolo Vermelho distroférrico por meio da técnica de TDR. Revista Brasileira de Ciência do Solo, Viçosa, v.35, n.5, p.1551-1559, 2011.

JACOBI, P.. Educação ambiental, cidadania e sustentabilidade. Cadernos de Pesquisa, São Paulo, n.118, p.189-205, 2003.

KLEIN, V. A.; REICHERT, J. M.; REINERT, D. J.. Água disponível em um Latossolo Vermelho argiloso e murcha fisiológica de culturas. Revista Brasileira de Engenharia Agrícola e

Ambiental, Campina Grande, v.10, n.3, p.646-650, 2006.
LONGHI, A. L. B.; BABY, A. L. T.; ÁVILA, G. R. P. T.; MOURA, P. S. C.. Quantificação de Desmatamentos na Bacia do Alto Paraguai no Estado de Mato Grosso - MT, com base nos estudos de Dinâmica de Desmatamentos utilizando séries temporais de imagens de satélites LANDSAT TM/ETM+. In: SIMPÓSIO DE GEOTECNOLOGIAS NO PANTANAL, 1. Anais. Campo Grande: Embrapa Informática Agropecuária/INPE, p.476-481, 2006.

MARCHÃO, R. L.; BALBINO, L. C.; SILVA, E. M.; SANTOS JUNIOR, J. D. G.; SÁ, M. A. C.; VILELA, L.; BECQUER, T.. Qualidade física de um Latossolo Vermelho sob sistemas de integração lavoura-pecuária no Cerrado. Pesquisa Agropecuária Brasileira, v.42, n.6, p.873-882, 2007.

PEREIRA, A. P. A.; ANGELOCCI, L. R; SENTELHAS, P. C.. Agrometeorologia: fundamentos e aplicações práticas. Guaiba: Agropecuária, 2002.

PEREIRA, A. R.. Simplificando o balanço hídrico de Thornthwaite-Mather. Bragantia, Campinas, v.64, n.2, p.311-313, 2005.

REICHARDT, K.; TIMM, L. C.. Solo, Planta e Atmosfera: conceitos, processos e aplicações. São Paulo: Manole, 2004.

ROLIM, G. S.; SENTELHAS, P. C.; BARBIERI, V.. Planilhas no ambiente EXCELTM para os cálculos de balanços hídricos normal, sequencial, de cultura e de produtividade real e potencial. Revista Brasileira de Agrometeorologia, Santa Maria, v.6, n.1, p.133-137, 1998.

RUIZ, H. A.; FERREIRA, G. B.; PEREIRA, J. B. M.. Estimativa da capacidade de campo de Latossolos e neossolos quartzarênicos pela determinação do equivalente de umidade. Revista Brasileira de Ciência do Solo, Viçosa, v.27, p.389-393, 2003. 
SANS, L. M. A.; GUIMARÃES, D. P.; AVELLAR, G.. Zoneamento de riscos climáticos para a cultura de milho na Região Centro-Oeste do Brasil e para o estado de Minas Gerais. Revista Brasileira de Agrometeorologia, v.9, n.3, p.1-10, 2001.
TORMENA, C. A.; ROLOFF, G.; SÁ, J. C. M.. Propriedades físicas do solo sob plantio direto influenciadas por calagem, preparo inicial e tráfego. Revista Brasileira de Ciência do Solo, Viçosa, v.22, p.301-309, 1998. 